\title{
Neurology Symposium
}

\author{
The Neurology Symposium was held on 4 October 2012 at the Royal College of Physicians of Edinburgh \\ P Foley \\ Research Fellow and Honorary Neurology Registrar, Division of Clinical Neurosciences, Western General Hospital, Edinburgh
}

DECLARATION OF INTERESTS The author was a member of the organising committee for this symposium

\author{
Correspondence to P Foley, \\ Bramwell Dott Building, \\ Division of Clinical Neurosciences, \\ Western General Hospital, \\ Edinburgh EH4 2XU, UK
}

\section{tel. +44 (0) I3I 5372922}

e-mail peterfoley@nhs.net

\section{INTRODUCTION}

Neurological disorders are common, and may present to a variety of specialists in a multitude of ways. The speakers at this symposium, many of whom were nonneurologists, reflected this and provided valuable insight, drawing on a considerable breadth and depth of expertise gained in clinical and academic practice, both in the UK and overseas.

\section{SESSION I - ACUTE NEUROLOGY AT THE FRONT DOOR}

Guy Thwaites (Reader in Infectious Diseases, Honorary Consultant in Infectious Diseases and Microbiology, Kings College and Guys and St Thomas' Hospital) discussed the general approach to infections of the central nervous system (CNS),' structuring his lecture around management decisions in a highly interactive clinical case of fever, headache and confusion. He emphasised the importance of a detailed history (particularly examining host immune factors and duration of symptoms in the case of possible tuberculous meningitis), careful investigation, and expedited antibiotic therapy. The evidence base for each clinical management decision was reviewed in detail.

Michael Eddleston (Scottish Senior Clinical Research Fellow, Clinical Pharmacology Unit, University of Edinburgh) continued with a review of acute poisoning, built around a series of clinical cases. He emphasised that neurological effects in acute poisoning are common, often including impairment of conscious level, movement and tone, nerve, neuromuscular junction and muscle function. The importance of actively seeking out and identifying 'toxidromes' (physiological manifestations of a potential toxin's mechanism of action) was discussed.

\section{SESSION 2 - ACUTE NEUROLOGY BEYOND THE FRONT DOOR}

Keith Muir (Professor of Clinical Imaging, University of Glasgow and Consultant Neurologist, Southern General Hospital, Glasgow) began by reviewing conventions for distinguishing migraine and stroke, before highlighting that these conventions may be overly simplistic. He emphasised clinical overlap in the two syndromes, including factors contributing to diagnostic difficulty such as changing patterns of migraine throughout life, and prolonged auras, as well as genetic conditions such as cerebral autosomal dominant arteriopathy with subcortical infarcts and leucoencephalopathy (CADASIL) in which both migraine and stroke are seen. $\mathrm{He}$ also discussed the management of patent foramen ovale (PFO) in secondary prevention following stroke when PFO is present - specifically the current lack of evidence for suggesting warfarin as compared to aspirin for treatment, and for suggesting surgical closure as compared to medical therapy. He reiterated that at a first presentation, differentiation between migraine and stroke may be extremely difficult, and strongly suggested that such patients be investigated fully.

Lucy MacKillop (Obstetric Physician, Women's Centre, Oxford University Hospitals NHS Trust) is one of only a few obstetric physicians in the UK. She discussed both neurological complications of pregnancy and management of underlying neurological conditions in pregnancy. This discussion was set in the context of audits of maternal deaths in the UK, ${ }^{2}$ demonstrating that neurological disease remains a significant cause of maternal mortality. She stressed that pregnant women with pre-existing neurological disorders should be identified early, and their condition kept under close review by a multi-disciplinary group, with full patient involvement.

\section{SESSION 3 - MANAGEMENT CHALLENGES}

John Mellers (Consultant Neuropsychiatrist, Maudsley Hospital, London) discussed common issues in the treatment of established dissociative (non-epileptic) seizures, in particular the phenomenon of dissociation, as well as predisposing, precipitating and maintaining factors. ${ }^{3}$ He discussed the role of liaison psychiatry and neuropsychiatry in management, including in identifying and addressing these factors. He reviewed a treatment model emphasising the key roles of explanation, reassurance, and giving information (including online information at www.epilepsysociety.org.uk, 
www.neurosymptoms.org and www.neadtrust.co.uk) to the patient. Many patients improve with these initial measures, although he also discussed the possible roles of some specific types of psychotherapy.

Mike Burdon (Consultant Ophthalmologist, Birmingham University Hospitals NHS Trust) reviewed the challenging management of idiopathic intracranial hypertension. He emphasised in particular the importance of ascertaining the presence (or otherwise) of papilloedema, exclusion of other causes of raised intracranial pressure, close monitoring of vision, consideration of co-morbid causes of headache (including migraine, chronic analgesic use and low intracranial pressure post-lumbar puncture), and patient-tailored treatment.

\section{SESSION 4 - ASSISTED DYING - WE NEED TO TALK ABOUT IT}

Neil Scolding (Council Member, Association of British Neurologists and Burden Professor of Clinical Neurosciences, University of Bristol) and Raymond Tallis (retired Professor of Geriatric Medicine, University of Manchester; retired Consultant Physician, Health Care of the Elderly, Salford; and Chair, Healthcare Professionals forAssisted Dying) delivered opposing yet complementary and thought-provoking discussions of some complex societal, ethical and legal aspects of the assisted dying debate. The discussion was set in the context of recent high-profile cases discussed in the international media, debate at the British Medical Association, ${ }^{4}$ and a recent Association of British Neurologists (ABN) working group statement opposing assisted dying - a statement which had broad, but not unanimous, support of the ABN membership. The quality of the complex discussions was underlined by challenging questions from the floor, including a discussion of the difficulty in defining patient groups to which any legislation might apply.

\section{TAKE-HOME MESSAGE}

The symposium covered much of the wide spectrum of patients, problems and solutions seen in modern neurology. In moving from expert discussion of 'front door' acute presentations to complex topical legal and ethical arguments, the best current evidence-based patient management was viewed in light of the difficult problems which still remain.

\section{REFERENCES}

I. Davies N,Thwaites G. Infections of the nervous system. Pract Neurol 20II; II: I2I-3I. http://dx.doi.org/I0.II36/jnnp.20II.2422I4

2. Centre for Maternal and Child Enquiries (CMACE). Savin mothers' lives: reviewing maternal deaths to make motherhood safer: 2006-2008. The eighth report on confidential enquiries into maternal deaths in the United Kingdom. BJOG 20I I; I I 8:I-203.

3. Brown RJ, Syed TU, Benbadis S et al. Psychogenic nonepileptic seizures. Epilepsy Behav 20I I;22:85-93. http://dx.doi.org/10.1016/j. yebeh.20II.02.016

4. Tallis R. Our professional bodies should stop opposing assisted dying. BMJ 20I2; 344:e4 I I5. http://dx.doi.org/I0. I I36/bmj.e4I I5

\section{CONFERENCING AND EVENTS}

The Royal College of Physicians of Edinburgh has a unique blend of rooms providing the perfect location for your conference, meeting or event. The Victorian Great Hall, galleried New Library and the Georgian Cullen Suite are wonderful settings for dinners and receptions. The modern Conference Centre seats up to 300 people in raked seating and is complemented by breakout rooms seating from 10 to 150 people, a keypad voting system and video conferencing. The College provides a stunning setting for weddings and receptions and is licensed for both civil and religious ceremonies. Discounts are available for Fellows and Members, medical conferences and charities.

For more information or for a quotation, please contact the Events Team on +44 (0) I 3 I 225 7324; email events@rcpe.ac.uk or visit http://www.rcpe-venue.co.uk

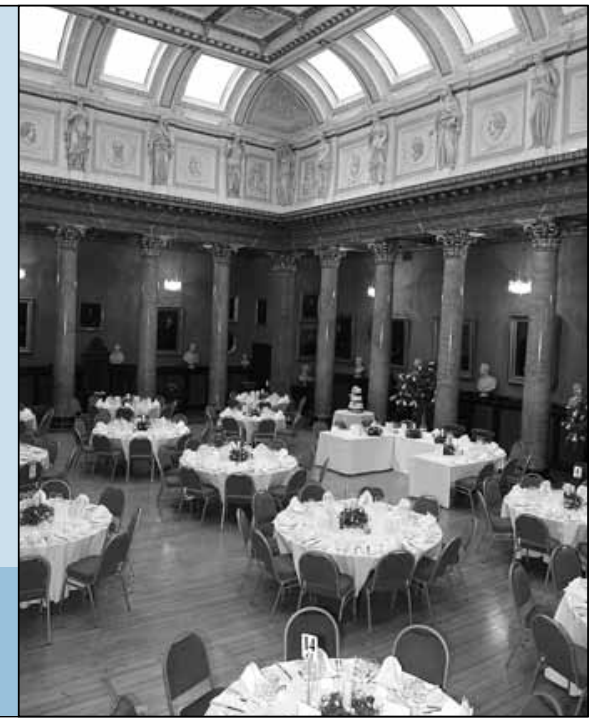

